\title{
Investigation of endocytosis and cytotoxicity of poly-d, I-lactide-poly(ethylene glycol) micro/nano-particles in osteoblast cells
}

This article was published in the following Dove Press journal:

International Journal of Nanomedicine

29 July 2010

Number of times this article has been viewed

\section{Weijia Wang \\ Shaobing Zhou \\ Laiyang Guo \\ Wei Zhi \\ Xiaohong $\mathrm{Li}$ \\ Jie Weng}

School of Materials Science and Engineering, Key Laboratory of Advanced Technologies of Material, Ministry of Education, Southwest Jiaotong University, Chengdou, Sichuan, People's Republic of China

Correspondence: Shaobing Zhou School of Materials Science and Engineering, Key Laboratory of Advanced Technologies of Material, Ministry of Education, Southwest Jiaotong University, Chengdou 610031, Sichuan, People's Republic of China Tel +86-28-87634023

Fax +86-28-87634649

Email shaobingzhou@swjtu.cn; shaobingzhou@hotmail.com

\begin{abstract}
Biodegradable polymer particles present a promising approach for intracellular delivery of drugs, proteins, and nucleic acids. Poly- $d, l$-lactide-poly(ethylene glycol) (PELA) copolymers with different weight ratios of polyethylene glycol (PEG) were used as drug carriers in the present study. PELA particles entrapped with fluorescein isothiocyanate (FITC) as a fluorescent marker were formulated using a double emulsion-solvent evaporation technique. The size and morphology of the particles were observed with scanning electron microscope (SEM), atomic force microscope (AFM), and laser diffraction particle size analyzer (LDPSA). The purpose in the present work was to investigate the cytotoxicity and the process of endocytosis of PELA particles with different contents of PEG and variable particle size using rat osteoblasts (OBs). The cytotoxicity of the particles was investigated using 5-dimethylthiazol2-yl-2,5-diphenyltetrazolium bromide (MTT) assay and flow cytometry. Results indicate that as the content of PEG in the polymer increased, so did cell survival. Endocytosis was observed through a light microscope and a fluorescence microscope; intracellular uptake and retention were determined quantitatively using fluorescence spectrophotometer (FSP). The results showed that as PEG content in PELA copolymer increased, there was a reduction in endocytosis of nanoparticles in osteoblasts.
\end{abstract}

Keywords: nanoparticles, endocytosis, cytotoxicity, intracellular trafficking, drug delivery

With the development of modern medicine and pharmacology, gene therapy becomes of increasing concern in the treatment of bone disease because it can increase therapeutic effects. Modern nanotechnology allows for a variety of choices in developing efficient systems for delivering diverse therapeutic agents ranging from small molecule drugs to biomacromolecules (eg, recombinant proteins, genes). ${ }^{1}$ Most of these therapeutic agents require intracellular uptake to deliver their therapeutic effect because their site of action is within the cell. However, the major limitation with macromolecular therapeutics is their inefficient intracellular uptake and susceptibility to degradation during uptake by endocytosis. ${ }^{2}$ Endocytosis is a conserved process in eukaryotes whereby extracellular substances are taken up into the cells usually by the invagination of plasma membrane forming vesicles. In addition to the classical clathrin- (or receptor-) mediated pathway, other endocytic mechanisms have been identified: phagocytosis, caveolae-mediated endocytosis, macropinocytosis, and clathrin- and caveolae-independent endocytosis. ${ }^{3-5}$ These various endocytic routes vary in the composition of coat, size of detached vesicles, and fate of internalized material. ${ }^{4-6}$

Development of nanoparticles as an efficient carrier for intracellular drug and macromolecular delivery is dependent on their efficient internalization and sustained 
retention inside the cell and drug activity. Over the past two decades, there has been a steady rise in the number of commercially available nanoparticle (NP) therapeutics. ${ }^{7-9}$ Several reports have included discussions of the internalization of polymeric nanoparticles into the cells by endocytic pathways. ${ }^{10-12}$ Biodegradable polymers such as $\operatorname{poly}(d, l$-lactic acid) (PLA), poly( $d, l$-lactic-co-glycolic acid) (PLGA), and $\operatorname{poly}(\varepsilon$-caprolactone) and their diblocked or multiblocked copolymers with PEG have been commonly used to form core - shell structured NPs to encapsulate a variety of therapeutic compounds. ${ }^{13-20}$ It has been shown that biodegradable nanoparticles formulated from PLGA rapidly escape the degradative endo-lysosomal compartment and are capable of delivering a variety of payloads into the cytoplasm. ${ }^{21-23}$ PLGA nanoparticles for delivery of therapeutics are of particular interest due to their biocompatibility, biodegradability, and ability to maintain therapeutic drug levels for sustained periods of time. The polymer matrix prevents the degradation of the drug and the duration and levels of drug released from the NPs can be easily modulated by altering the formulation. ${ }^{24}$ The application of biodegradable polymeric NPs for drug delivery has been gaining momentum and shows significant therapeutic potential. ${ }^{25-27}$

In our research group PELA microspheres used as drug delivery systems have been widely studied, from the preparation method to the factors influencing the in vitro degradation profiles and in vitro drug release profiles. ${ }^{13,28}$ However, the biological evaluation for PELA microspheres was rarely referred to in our previous report. In this paper, four kinds of microspheres based on biodegradable polymers such as PLA, and PELA with PEG content of $10 \%, 20 \%$, or $30 \%$, were prepared by a double emulsion-solvent evaporation technique to investigate cytotoxicity and phagocytosis. Here the abbreviations PELA10, PELA20, and PELA30 stand for PELA with PEG content of $10 \%, 20 \%$, and $30 \%$, respectively. In addition, PELA10 particles with an average size of $1 \mu \mathrm{m}$ and $10 \mu \mathrm{m}$ were also prepared to study the effect of particle size on the endocytosis in osteoblast cells.

\section{Materials and methods \\ Materials}

$\operatorname{Poly}(d, l$-lactide) (PLA) and poly- $d, l$-lactide-poly(ethylene glycol) (PELA) with PEG weight ratios of $10 \%, 20 \%$, and $30 \%$ and molecular weight $(\mathrm{Mw})$ of $4 \mathrm{kDa}$ were synthesized by ring-opening polymerization in our laboratory as our previous report. ${ }^{14}$ The $\mathrm{Mw}$ and its distribution were measured with gel permeation chromatograph (GPC, Waters ALC/GPC 244, USA) using polystyrene as standards.
Polyvinyl alcohol (PVA, $\mathrm{M}_{\mathrm{n}}$ of $130,000 \mathrm{~g} \cdot \mathrm{mol}^{-1}$, degree of hydrolysis 88 ) was purchased from Shanghai Petrochemical Industry Company (China). 3-(4,5-Dimethylthiazol-2-yl)2,5-diphenyltetrazolium bromide (MTT) was purchased from Sigma. The cells were obtained from the neonatal mandibular osteoblasts of a rat. All the chemicals used in this research were of analytical reagent grade from the commercial market and have not been further purified.

\section{Fabrication of PELA particles}

Both microspheres and nanoparticles were prepared by double emulsion method $(\mathrm{W} / \mathrm{O} / \mathrm{W})$ based on solvent evaporation. ${ }^{13}$ Here, we fabricated the particles with micro/nano scaled sizes by adjusting the stirring speed and PVA concentrations. Briefly, $0.1 \mathrm{~g}$ PLA or PELA was dissolved in $5 \mathrm{~mL}$ mixed solution (methylene chloride: acetone $=1: 4 \mathrm{v} / \mathrm{v}$ ) and emulsified with $500 \mu \mathrm{L}$ of FITC as a fluorescent marker under stirring for 15 minutes at $700 \mathrm{rpm}$ to form a stable initial emulsion. The resulting emulsion was then added dropwise into $50 \mathrm{~mL} \mathrm{3 \%}$ PVA solution and emulsified for 1 hour at 1000 rpm using overhead whisk (R-S, Shanghai Shenshun Biotechnology Company, China) to form a double emulsion system. Finally, $10 \mathrm{~mL} 1 \%$ isopropanol solution was poured into the double emulsion and stirred for about 6 hours in fuming cupboard. After the organic solvent evaporated completely, the particles were collected by centrifugation (Avanti ${ }^{\mathrm{TM}}$ J-301, Beckman Coulter, USA) at 15,000 rpm. The resultant particles were rinsed with distilled water and centrifuged three more times, then lyophilized overnight and stored at $4{ }^{\circ} \mathrm{C}$.

\section{Characterization of these particles}

The mean size and distribution of these microspheres as determined using a laser diffraction particle size analyzer (LA-920, Horiba, Japan). Microspheres were resuspended in distilled water and ultrasonic to prevent microspheres aggregation. The microsphere solution was then poured into the sample tank of particle size analyzer. The mean size and size distribution of the nanoparticles $(1.0 \mathrm{mg} / \mathrm{mL})$ were determined by dynamic light scattering (DLS) using a Zeta-Sizer, Malvern Nano-ZS90 (Malvern Ltd., Malvern, UK). Each measurement was also repeated three times and the average value reported.

The surface morphology of the particles was examined by SEM (FEI, Quanta 200) and AFM (CSPM 5000, China). Several solution droplets containing particles were placed on the SEM sample stage. The properties of the nanospheres were also measured by tapping-mode atomic force 
microscopy (AFM) (CSPM5000, Being, China). The AFM sample was prepared by casting a dilute micelles solution on a solid silicon piece, which was then dried under vacuum. AFM technique is an effective, widely applied method for obtaining surface morphological information. ${ }^{30}$ Tapping mode atomic force microscopy is a technique for measuring the topography and properties of surfaces involving a microcantilever with a tip at one end that is excited into an oscillation near its resonance frequency. The cantilever-tip assembly is positioned vertically such that the tip touches the surface at the bottom of its down-stroke and is then scanned over the surface. The oscillation of the cantilever is affected by the topography of the surface, the local surface properties, and the feed back controller, which maintains the amplitude of the oscillation at a fixed set-point value. The vertical movements of the stage needed to maintain constant oscillation amplitude are used to draw the topography image and the phase lag of the oscillation relative to the excitation force is used to draw the phase image.

\section{Cytotoxicity assay}

The cytotoxicity of the particles was evaluated using an MTT assay and flow cytometry. OBs from SD rat were cultured in Dulbecco's modified Eagle's medium (DMEM) supplemented with $10 \%$ fetal bovine serum (FBS) at $37{ }^{\circ} \mathrm{C}$ in a $5 \% \mathrm{CO}_{2}$ incubator. Cells were seeded in 24 -well plates in $2 \mathrm{~mL}$ medium per well at a density of 10,000 cells/well for 6 hours. The medium was then replaced with $2 \mathrm{~mL}$ of mediumcontaining particles at $0.3 \mathrm{mg} / \mathrm{mL}$ and $0.6 \mathrm{mg} / \mathrm{mL}^{30}$ and incubated for 24 hours under $5 \% \mathrm{CO}_{2}$ at $37^{\circ} \mathrm{C}$. After 24 hours, the culture medium was removed from cell monolayers and cultured in 96-well plates. Each well was reconstituted with $0.2 \mathrm{~mL}$ supplemented RPMI-1640 containing $1 \mathrm{mg} / \mathrm{mL}$ MTT and incubated the cultures for $2-4$ hours at $37^{\circ} \mathrm{C}$. The supernatants were removed from the wells, and then $0.2 \mathrm{~mL}$ dimethyl sulfoxide (DMSO) per well was added in isopropanol and mixed with the content of the wells thoroughly. Finally, the plates were read in an automated microplate spectrophotometer (ELX800 Biotek, USA) at $570 \mathrm{~nm}$ as reference. Every 24 hours the same tests was performed as mentioned above until 72 hours. Cell viability was determined by the following formula:

$$
\text { Cell viability }(\%)=\frac{\mathrm{OD}(\text { test well })}{\mathrm{OD}(\text { reference well })} \times 100 \%
$$

In vitro compatibility of the blank nanoparticles was also determined by MTT assays using OBs. All the results obtained from MTT assays were confirmed by repeating the experiment on at least three independent occasions and testing in triplicate each time.

The flow cytometer employed was a Coulter EPICS-XL (Coulter, Miami, FL, USA). The cells were seeded in 6-well plates in $2 \mathrm{~mL}$ medium per well at a density of 10,000 cells/ well for 6 hours for flow cytometry. The medium was then replaced with $2 \mathrm{~mL}$ of medium-containing particles at $0.3 \mathrm{mg} / \mathrm{mL}$ and incubated under $5 \% \mathrm{CO}_{2}$ at $37^{\circ} \mathrm{C}$. When the amount of the cells reached $10^{5}$ or more for each sample, the cells were gathered and frozen for preservation. ${ }^{31}$

\section{Endocytosis of nanospheres in OBs}

OBs from SD rat were seeded in 12-well plates (Falcon ${ }^{\circledR}$, Becton Dickinson) in $2 \mathrm{~mL}$ medium per well at a density of 50,000 cells/well for 6 hours. The medium was then replaced with $2 \mathrm{~mL}$ of medium-containing nanospheres and incubated under $5 \% \mathrm{CO}_{2}$ at $37^{\circ} \mathrm{C}$. The time-dependent cellular uptake of nanoparticles was further determined. To study it, cells were incubated with a suspension of nanoparticles $(100 \mu \mathrm{g} /$ $\mathrm{mL}$ ) for different time periods. The endocytosis nanospheres in OBs were studied using fluorescence microscope. A quantitative analysis of the nanoparticles level was used to follow endocytosis of nanoparticles by fluorescence spectrophotometer. ${ }^{32}$ The fluorescent solutions with predetermined concentrations were employed to establish the standard curves, and subsequently, we could obtain the fluorescence intensity inside the particles, which further reflected the endocytosis of nanospheres in OBs.

\section{Intracellular translocation studies}

The cell culture was incubated with nanoparticles (25 $\mu \mathrm{g} / \mathrm{mL}$ ) for 12 hours at $37{ }^{\circ} \mathrm{C}$. After washing three times with PBS, the cells were collected by centrifugation and subsequently fixed with $3 \%$ glutaraldehyde for 2 hours at $4{ }^{\circ} \mathrm{C}$, and finally treated by osmium tetroxide for 30 minutes. The sample was dehydrated using a graded acetone series. The cells were placed in a pure acetone and Epon 812 epoxy, respectively, for 30 minutes and then embedded in Epon 812 epoxy at $60{ }^{\circ} \mathrm{C}$ for 48 hours. Ultrathin $(70 \mathrm{~nm})$ sections were cut with a diamond knife and stained with lead and uranium. The sample was examined using TEM (Hitachi H-7650).

\section{Statistical analysis}

Statistical analysis was performed using SPSS version 13.0. ANOVA was used to analyze statistical comparisons between groups. The level of significance was set at $P<0.05$. 


\section{Results and discussion}

\section{Characterization of the particles}

All particles were prepared by double emulsion method $(\mathrm{W} / \mathrm{O} / \mathrm{W})$ based on solvent evaporation. ${ }^{28}$ Our research group has previous experience with preparing nano- and micro-scaled particles. The average size of the particles can be controlled by adjusting the monomer ratio in copolymers' backbone and altering the parameters of preparation technology. ${ }^{13,28}$ Here, based on our previous research, the particles with different average size were easily fabricated. Figure 1A displays the mean diameter and its polydispersity (Pdi) of the particles. PLA-n, PELA10-n, PELA20-n, PELA30-n denote nanospheres while PELA10-1, PELA10-10 represent the microspheres with real average size of 1.85 and $9.92 \mu \mathrm{m}$, respectively, as shown in Figure 1A. The average diameters of PLA-n, PELA10-n, PELA20-n, and PELA30-n are $207 \pm 21 \mathrm{~nm}, 208 \pm 8 \mathrm{~nm}, 202 \pm 17 \mathrm{~nm}$, and $183 \pm 12 \mathrm{~nm}$, respectively (Figure 1B).

Typical scanning electron micrographs (SEM) (Figure 2) illustrate that all particles have a characteristic round shape and take on a good dispersion. The diameter and distribution of the particles are very consistent with the result detected by the laser diffraction particle size analyzer (Figure 1B). Meanwhile, PLA-n, PELA10-n, PELA20-n, and PELA30-n are further observed by AFM (Figure 3), which also indicate that they have excellent dispersibility in aqueous system and good spherical morphology.

\section{Cytotoxicity assay of the particles}

PELA is widely used in drug delivery system because of its good biocompatibility. The main purpose in this experiment was to study the treatment of bone diseases. So osteoblast cells were used to assess cellular cytotoxicity of PELA copolymer in form of particles. Following 6 hours of exposure to the particles, cell viability was assessed by the MTT assay. The results were plotted onto a fitted curve and expressed as treatment over control $(\mathrm{T} / \mathrm{C})$ values for cell survival. Both nano- and micro-particles did not cause significant cytotoxicity and cells had a normal shape as observed through inverted light microscope (Figure 4a). In addition, the letters $\mathrm{A}, \mathrm{B}, \mathrm{C}, \mathrm{D}, \mathrm{E}$, and $\mathrm{F}$ were used to represent PLA-n, PELA10-n, PELA20-n, PELA30-n, PELA10-1, and PELA10-10, respectively. From Figure 4a, it can be seen that osteoblasts in the nanosphere groups have a better growth compared to the microspheres group in the original period of 3 days of incubation, which indicates that these nanospheres are more biocompatible. In the microspheres group there
A

\begin{tabular}{lllll}
\hline Particles & $\begin{array}{l}\text { PEG content } \\
(w t . \%)\end{array}$ & Mw $(\mathrm{kDa})$ & Mean diameter & Pdi \\
\hline PLA-n & 0 & 13.0 & $207 \pm 12 \mathrm{~nm}$ & $0.31 \pm 0.071$ \\
PELA10-n & 10 & 15.5 & $208 \pm 8 \mathrm{~nm}$ & $0.271 \pm 0.092$ \\
PELA20-n & 20 & 13.3 & $195 \pm 5 \mathrm{~nm}$ & $0.192 \pm 0.045$ \\
PELA30-n & 30 & 12.3 & $180 \pm 7 \mathrm{~nm}$ & $0.17 \pm 0.052$ \\
PELA10-1 & 10 & 15.5 & $1.85 \pm 0.78 \mathrm{~nm}$ & $0.52 \pm 0.12$ \\
PELA10-10 & 10 & 15.5 & $9.92 \pm 0.21 \mathrm{~nm}$ & $0.38 \pm 0.095$ \\
\hline
\end{tabular}

B

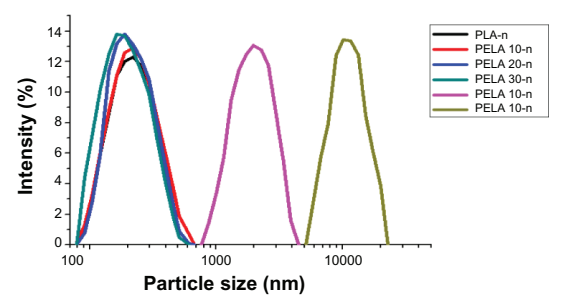

Figure I A) Summary of characterization of particles. B) Size distribution detected by laser diffraction particle size analyzer.

are many particles in the culture medium. It can be seen that more and more particles are aggregated from days 1 to 3 of incubation. This could indicate that microspheres are hardly phagocytized due to their large size. Figure $4 \mathrm{~b}$ shows that for all nanosphere groups, as the PEG content in the polymer increased, the cell viability also increased from 1 to 3 days $(P<0.05)$. The cell viability of PELA30-n group was about $85 \%$ while the others were near $80 \%$ on the first day. It demonstrates that PELA30-n has a better biocompatibility compared to the other nanospheres. The reason may be that with the increase of PEG content in the copolymer, the amount of particles phagocytized by the cells was decreased, which resulted in less cell cytotoxicity. The mechanism may be that PEG interacts with the cell membrane probably by association with its phospholipids, and this interaction may stabilize the membrane. ${ }^{24}$ For these particles with the same
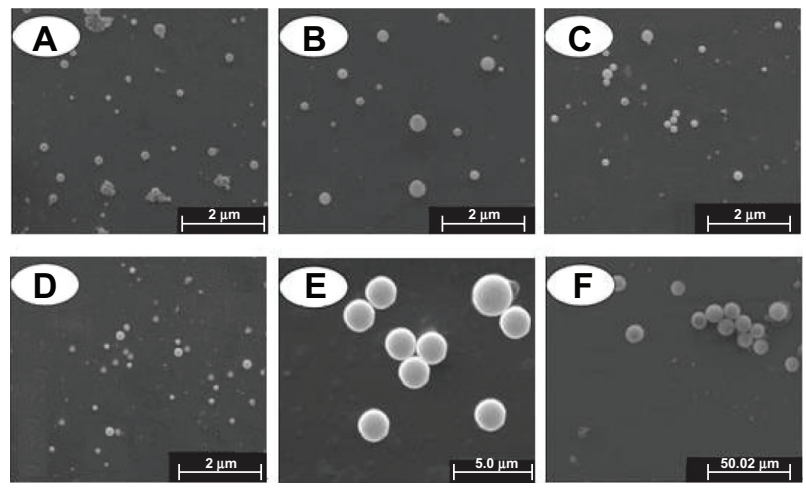

Figure 2 Morphology of particles detected by SEM. A, B, C, D, E, and F denote PLA-n, PELAI0-n, PELA20-n, PELA30-n, PELA I0-I, and PELAI0-I0, respectively. 

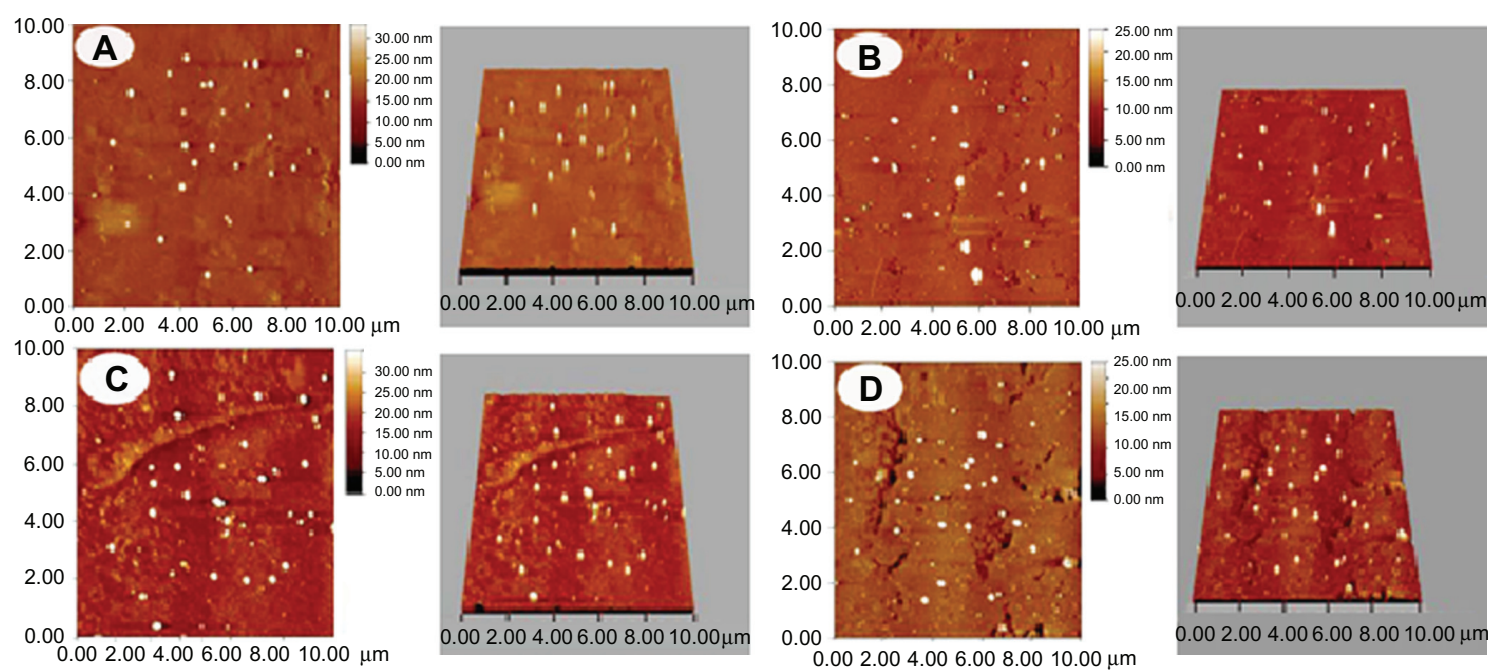

Figure 3 Morphology of nanospheres detected by AFM. A, B, C, and D denote PLA-n, PELAI0-n, PELA20-n, PELA30-n, respectively. Samples were prepared for AFM investigation.

polymer (PELA10-1 and PELA10-10), it can be deduced that as the size and concentration of these particles increased, cell survival was reduced. It has been reported that the particle concentration influences cell survival. ${ }^{34}$ With the increase in size, the cell phagocytosis reduced but in the culture medium and the microspheres may be aggregated, which causes the concentration around osteoblast to be higher. Consequently, cell survival was $5 \%-10 \%$ lower than that of other particles at the same period. These results were also demonstrated through flow cytometry.

To support the MTT data further, flow cytometry was also employed. In the experiment, the cells were seeded in 6-well plates in $2 \mathrm{~mL}$ medium per well at a density of 10,000 cells/ well for 6 hours. The medium was then replaced with $2 \mathrm{~mL}$ of medium-containing particles at $0.3 \mathrm{mg} / \mathrm{mL}$ and incubated under $5 \% \mathrm{CO}_{2}$ at $37{ }^{\circ} \mathrm{C}$. When the amount of cells reached $10^{5}$ or more, the cells were gathered. In Figure 5A, B, C, D, E, and F represent the same as those in Figure 4. As shown in Figure 5A, there appeared to be two peaks in each figure from 1 to 3 days. Gates were set to distinguish the staining of the cells in the gates and all cells, which was measured as mean fluorescence intensity (MFI) and peak position of fluorescence intensity or relative number of positive cells (\%), depending on the agent. ${ }^{32}$ Simultaneously, from the data in Figure 5A, both the amount of total cells and the cell apoptosis can be calculated. It can also be seen that the amount of cell apoptosis in the microsphere groups was generally higher than those in the nanosphere groups at the same time. Figure 5B shows the cell apoptosis rate derived from flow cytometry. The peak position of fluorescence intensity of the cells in population of the cell apoptosis stained with PI was $14.1 \pm 0.7,15.6 \pm 1.21,10.9 \pm 0.3,10.8 \pm 0.28$, $15.9 \pm 1.06$, and $21.7 \pm 1.04$, respectively, after 24 hours, and $9.6 \pm 0.54,6.2 \pm 2.13,7.1 \pm 0.14,5 \pm 1.31,8.7 \pm 0.5$, and $14.5 \pm 0.82$, respectively, after 48 hours, and $8.3 \pm 0.85$, $3.7 \pm 0.24,3.7 \pm 0.096,3.7 \pm 0.4,7.4 \pm 0.34$, and $10.4 \pm 0.83$, respectively, after 72 hours (Figure 5B). Incubated from 1 to 3 days, the cell apoptosis rate decreased gradually. The results were in strong agreement with those gained in the MTT assay.

\section{Endocytosis of the nanospheres in OBs}

In recent years, nanoparticles have attracted attention for use as delivery vehicles for therapeutic drugs since they can be designed to slip between intercellular spaces, enter cells, or transport directly through biological barriers to access disease sites. ${ }^{1,34}$ Particles loaded with fluorescent dyes are frequently used to study cellular uptake..$^{33}$ So FITC was loaded in the nanospheres. Figure 6A shows the cellular uptake of PLA-n, PELA10-n, PELA20-n, and PELA30-n. As FITC was assumed to disperse evenly in the particles, the fluorescence intensity was linearly proportional to the amount of particles in the cells. So the amount of cellular uptake was given at each time point by testing the fluorescence intensity. The time-dependent increase of uptake was observed for all nanoparticles between 2 to 24 hours of incubation. Nanoparticle uptake was relatively rapid during the original 2 hours of incubation from slope rate of curve. PELA30-n showed the lowest uptake dose while PLA-n had the highest uptake dose. PELA10-n and PELA20-n were engulfed into cells of a similar amount. It can be seen that from 0 to 24 hours, the number of nanoparticles phagocytized by cells was significant 
A

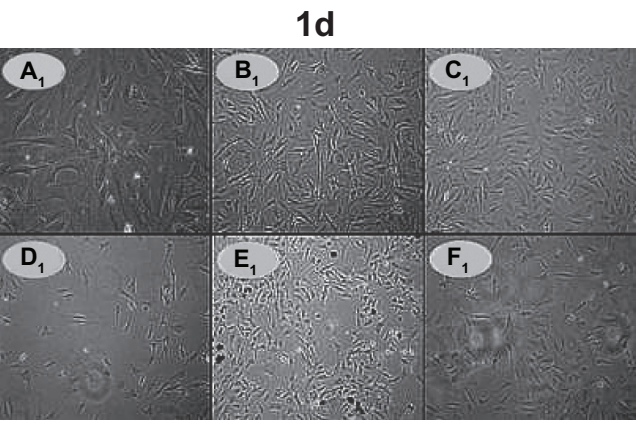

2d

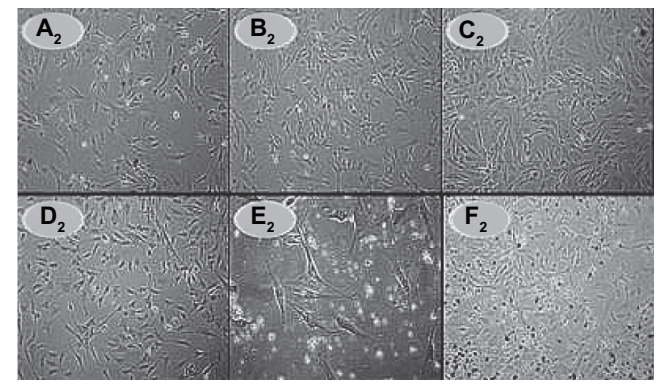

$3 d$

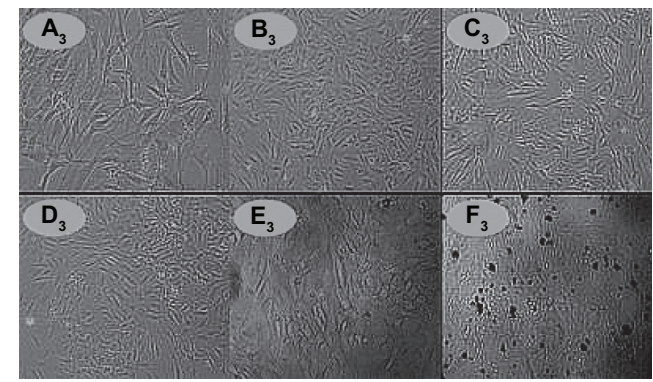

B

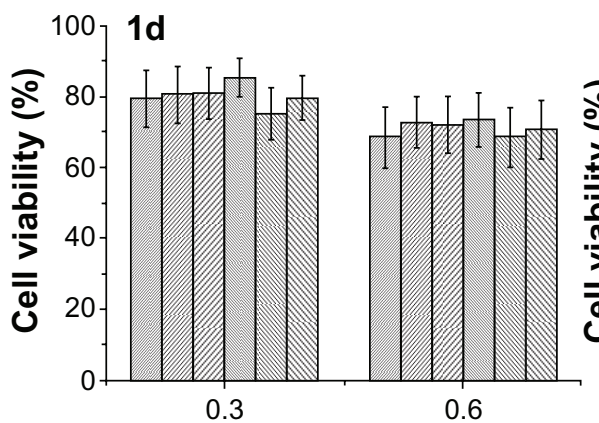

Materials concentration $(\mathrm{mg} / \mathrm{mL})$ Materials concentration $(\mathrm{mg} / \mathrm{mL})$

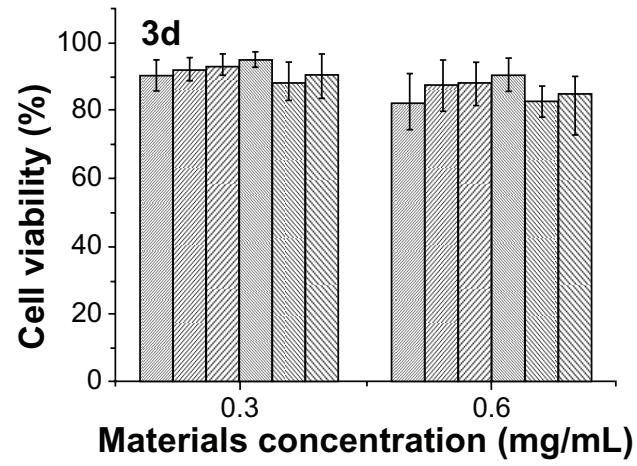

Figure 4 A) Optical microscopic observation $(\times 200)$ of osteoblasts incubated with PLA-n (A), PELAI0-n (B), PELA20-n (C), PELA30-n (D), PELA I0-I (E), and PELAI0-I0 (F) particles from I to 3 days. B) Viability of osteoblasts from I to 3 days by MTT assay, $P<0.05$.

different. The reason may be that the nanospheres were recognized with difficultly as a foreign body by osteoblasts due to existence of the hydrophilic PEG. Due to the hydrophilicity of PEG, the nanoparticles may be adhered to osteoblasts difficultly. So the number of nanospheres phagocytized is low. Cells would prefer to attach to more hydrophobic polymers and PEG causes the polymer of choice to render the surfaces of particles repellent to the adsorption of proteins and resistant to cellular recognition. Another aspect is the decoration of the PEGylated surfaces with suitable ligands for cell-specific recognition and targeting. ${ }^{35,36}$ These results were further supported by fluorescence microscopy observation.

Fluorescence micrographs of osteoblasts indicated that nanoparticle uptake was an endocytic process. To follow the 
A

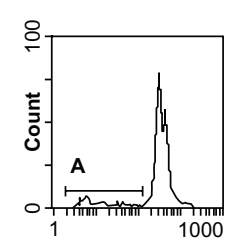

$1 d$
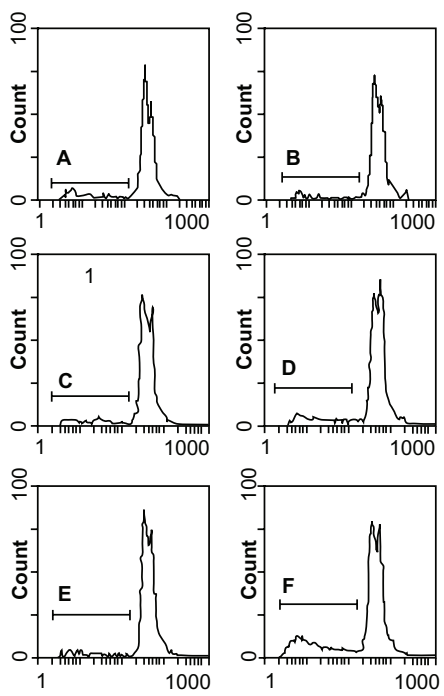

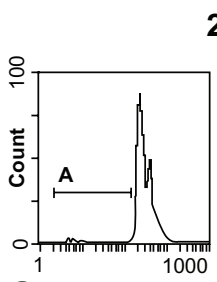

2d
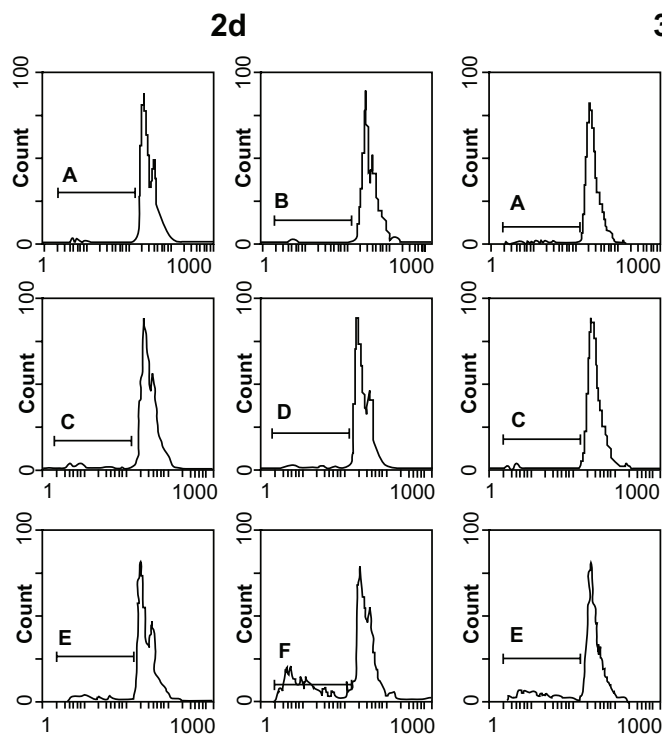

3d
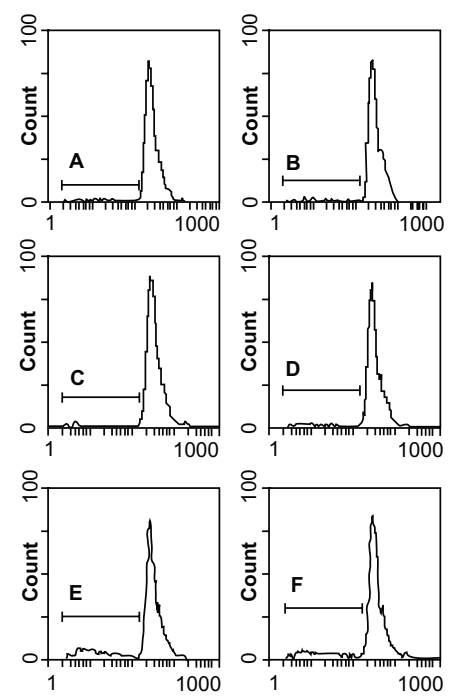

B

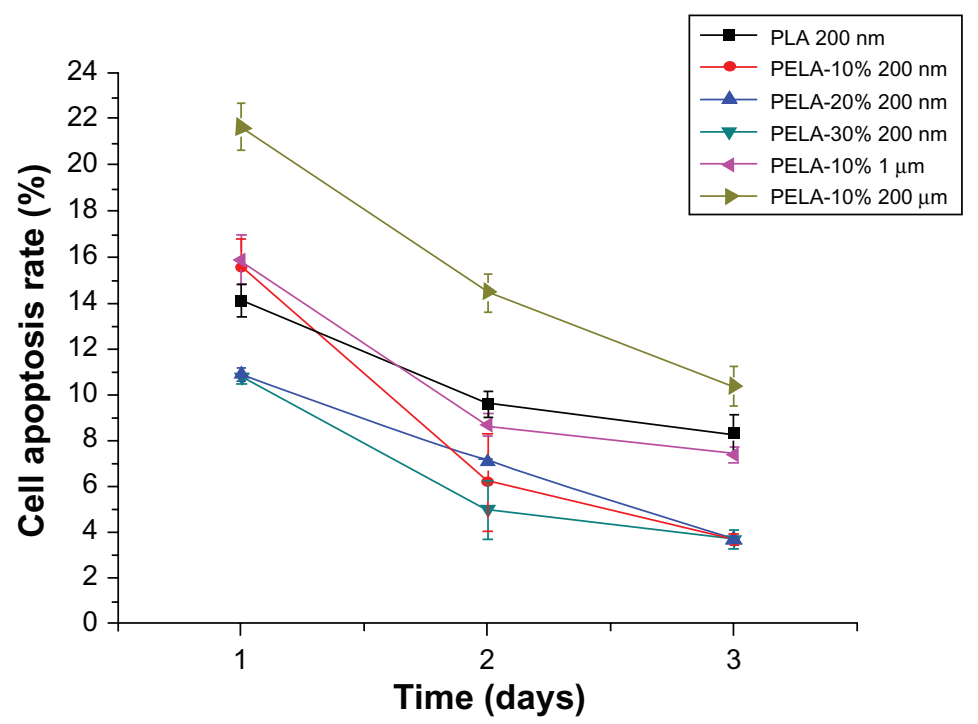

Figure 5 Cell apoptosis profiles of osteoblasts as a function of incubation time $\left(0.3 \mathrm{mg} / \mathrm{mL}, 37^{\circ} \mathrm{C}\right)$ detected by flow cytometer $\left.\mathbf{A}\right)$ and cell apoptosis rate of osteoblasts by flow cytometer B).

dynamics of intracellular uptake of nanoparticles, we took a series of fluorescence micrographs after these nanoparticles were dispersed in the cell culture (Figure 6B). It showed the microscopic images of osteoblast cells incubated with PLA, PELA10, PELA20, and P ELA30 nanoparticles with 0, 2, 8, and 16 hours at $37^{\circ} \mathrm{C}$. It can be observed that more particles were engulfed with time prolongation. Since the nanoparticles were added as a concentrated stock suspension on the top of the cell in the medium, the background fluorescence appears to be increasing as the particles are dispersing in the medium. A series of images were recorded at the different time points to illustrate that as the PEG content increased, the content of nanoparticles in osteoblast was reduced. Most
PLA-n and PELA10-n were engulfed before 8 hours compared to PELA20-n and PELA30-n. In terms of the single cell, there was a difference in the fluorescence intensity. This may be because the fluorescence intensity reflected the whole situation, and the different nanoparticles were phagocytized between 2 and 8 hours. The existence of PEG in nanoparticles can lead to nanoparticles being difficult to be phagocytized. PEG interacts with the cell membrane probably by association with its phospholipids, and this interaction may stabilize the membrane, so the nanospheres were not always recognized as foreign bodies by osteoblasts.

In the treatment of disease, the cellular uptake of the nanoparticles is also an important attribution because small 


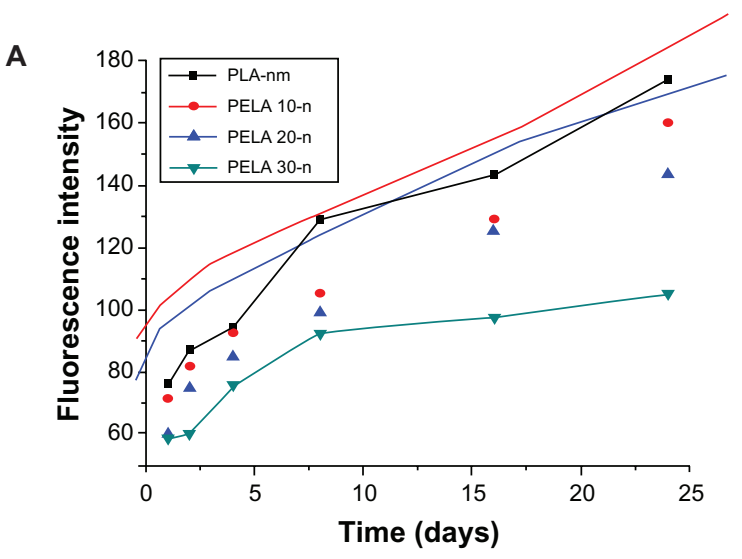

B

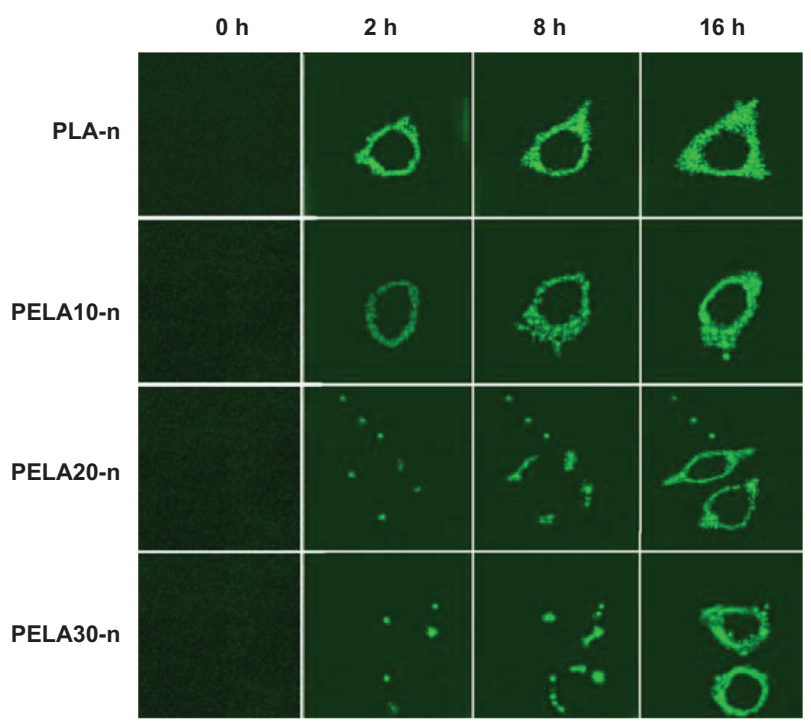

Figure 6 A) Fluorescence intensity of nanospheres in osteoblasts detected by fluorescence spectrophotometer. B) Fluorescent microscopy utilized to assess cellular uptake of nanospheres as a function of incubation time $\left(0.3 \mathrm{mg} / \mathrm{mL}, 37^{\circ} \mathrm{C}\right)$. Osteoblasts were incubated with the nanospheres under the condition as indicated above each image, and samples were prepared for fluorescence microscope $(\times 200)$ investigation. Bars $=20 \mu \mathrm{m}$.

molecular drugs entrapped in the nanoparticles can enter the cells through endocytosis rather than passive diffusion. ${ }^{35}$ Therefore, cellular uptake efficiency of drug-loaded nanoparticles affects the therapeutic effects. From Figure 4A, these nanosphere groups display the highest uptake dose while the microsphere group has the lowest uptake dose. The reason may be that the particles with smaller size $(200 \mathrm{~nm})$ were phagocytized easily by osteoblast compared to the particles with larger size (1 and $10 \mu \mathrm{m})$. It could prove that osteoblasts have selective phagocytosis depending on the size of foreign body. From Figure 6, it was found that the cellular uptake of PLA-n was the most efficient at all time points while the cellular uptake proportion of PELA30-n was the lowest. A number of factors have been reported as influencing the uptake efficiency of nanoparticles including particle size, ${ }^{37}$ cell lines and cell densities, hydrophilic proportion of copolymers, and surface charge. ${ }^{38}$ According to our study results, particle size was found to be the main character in determining the cellular uptake efficiency. Moreover, the hydrophilic proportion of the nanoparticles also had an effect on the uptake dose, as PLA-n, PELA10-n, PELA20-n, and PELA30-n (similar in particle size but different in the hydrophilic ratio) exhibited different uptake proportion.

Generally, the cellular uptake of nanoparticles is completed by enclosing them into endosomes. The early endosomes mature into late endosomes or multivesicular bodies, and then to lysosomes, which accompanies a significant drop in $\mathrm{pH} .{ }^{39,40} \mathrm{Next}$, the intracellular fate of these nanoparticles was inspected by TEM. As shown in the TEM images (Figure 7), some of the nanoparticles could be localized in the endosomes and lysosomes. Around the cell membrane, it can be seen that some organelles were emerging inside of which have nanospheres. More nanospheres could be found inside the cell.

\section{Conclusions}

In this study micro- and nanospheres were prepared using PLA, PELA10, PELA20, and PELA30 polymers as the matrix. The particles with average diameter of about $200 \mathrm{~nm}, 1.85 \mu \mathrm{m}$, and $9.92 \mu \mathrm{m}$ were obtained using the $\mathrm{W} / \mathrm{O} / \mathrm{W}$ emulsion method. The cytotoxicity of particles with different sizes and PEG contents were investigated

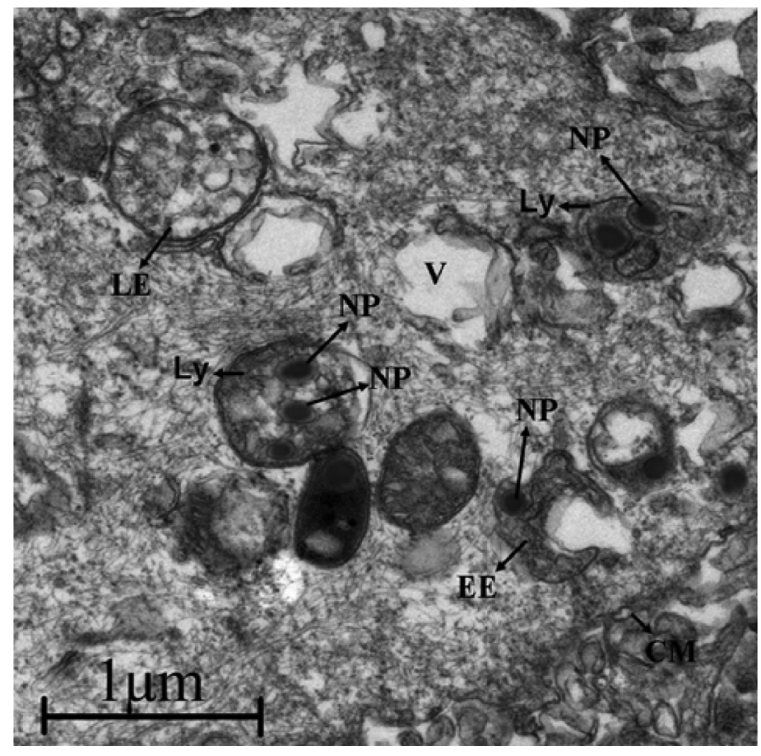

Figure 7 TEM photo showing intracellular fate of nanospheres. Some nanospheres were localized in endosomes and lysosomes.

Abbreviations: Ly, lysosome; LE, late endosomes; $\mathrm{EE}$, early endosomes; $\mathrm{V}$, vacuole; CM, cell membrane; NP, nanoparticles. 
using MTT assay and flow cytometry. Results indicated that as the PEG content in the polymer increased, cell survival also increased. In particular PELA30 polymers had a better cell compatibility compared to the other materials. For the same polymer, when the size and concentration of the particles were increased, cell survival was reduced. The intracellular uptake and retention of nanoparticles were further performed in osteoblasts. The fluorescence data illustrated that as the PEG content in the polymer increased, the content of nanoparticles in the osteoblast was reduced. Therefore, the nanoparticulate delivery system would be useful in exploring nanoparticles for intracellular delivery of therapeutic agents, as they promise to overcome many of the obstacles inherently associated with the administration of certain drugs, vaccines, plasmid DNA, and RNAi. ${ }^{41-45}$

\section{Acknowledgment/disclosure}

This work was partially supported by the National Natural Science Foundation of China (30970723), Programs for New Century Excellent Talents in University, Ministry of Education of China (NCET-07-0719), and Sichuan Prominent Young Talent Program (08ZQ026-040).

\section{References}

1. Moghimi SM, Hunter AC, Murray JC. Long-circulating and targetspecific nanoparticles: theory to practice. Pharm Rev. 2001;53: 283-318.

2. Riezman H, Woodman PG, Meer G, Marsh M. Molecular mechanisms of endocytosis. Cell. 1997;91:731-738.

3. Johannes L, Lamaze C. Clathrin-dependent or not: is it still the question? Traffic. 2002;3:443-451.

4. Conner SD, Schmid SL. Regulated portals of entry into the cell. Nature. 2003;422:37-44.

5. Khalil IA, Kogure K, Akita H, Harashima H. Uptake pathways and subsequent intracellular trafficking in nonviral gene delivery. Pharm Rev. 2006;58:32-45.

6. Lamaze C, Schmid SL. The emergence of clathrin-independent pinocytic pathways. Curr Opin Cell Biol. 1995;7:573-580.

7. Langer R. Drug delivery and targeting. Nature. 1998;392:5-10.

8. Ferrari M. Cancer nanotechnology: opportunities and challenges. Nat Rev Cancer. 2005;5:161-171.

9. Zhang L, Gu FX, Chan JM, Wang AZ, Langer RS, Farokhzad OC. Nanoparticles in medicine: therapeutic applications and developments. Clin Pharm Ther. 2008;83:761-769.

10. Jensen KD, Nori A, Tijerina M, Kopeckova P, Kopecek J. Cytoplasmic delivery and nuclear targeting of synthetic macromolecules. J Control Release. 2003;87:89-105.

11. Panyam J, Labhasetwar V. Dynamics of endocytosis and exocytosis of poly(D,L-lactide-co-glycolide) nanoparticles in vascular smooth muscle cells. Pharm Res. 2003;20:212-220.

12. Meng W, Parker TL, Kallinteri P, et al. Uptake and metabolism of novel biodegradable poly(glycerol-adipate) nanoparticles in DAOY monolayer. J Control Release. 2006;116:314-321.

13. Zhou SB, Deng XM, Li XH. Investigation on a novel core-coated microspheres protein delivery system. $J$ Control Release. 2001;75 $(1-2): 27-36$.
14. Zhou SB, Deng XM,Yang H. Biodegradable copolymer of poly (ethylene glycol)-co-poly ( $\varepsilon$-caprol actone):characterization and its use in controlled release system. Biomaterials. 2003;24(20): 3563-3570.

15. Farokhzad OC, Cheng J, Teply BA, Sherifi I, Jon S, Kantoff PW. Targeted nanoparticle-aptamer bioconjugates for cancer chemotherapy in vivo. Proc Natl Acad Sci. 2006;103:6315-6320.

16. Zhang L, Radovic-Moreno AF, Alexis F, Gu FX, Basto PA, Bagalkot V. Codelivery of hydrophobic and hydrophilic drugs from nanoparticleaptamer bioconjugates. Chem Med Chem. 2007;2:1268-1271.

17. Cheng J, Teply BA, Sherifi I, Sung J, Luther G, Gu FX. Formulation of functionalized PLGA-PEG nanoparticles for in vivo targeted drug delivery. Biomaterials. 2007;28:869-876.

18. Gu F, Zhang L, Teply BA, Mann N, Wang A, Radovic-Moreno AF. Precise engineering of targeted nanoparticles by using self-assembled biointegrated block copolymers. Proc Natl Acad Sci U S A. 2008;19: 2586-2591.

19. Wei XW, Gong CY, Gou ML, Fu SZ, Guo QF, Qian ZY. Biodegradable poly (<epsilon $>$-caprolactone)-poly(ethylene glycol) copolymers as drug delivery system. Int $J$ Pharm. 2009;381:1-18.

20. Gou ML, Zheng XL, Men K, Zhang J, Wang BL, Qian ZY. Selfassembled hydrophobic honokiol loaded MPEG-PCL diblock copolymer micelles. Pharm Res. 2009;26:2164-2173.

21. Panyam J, Zhou WZ, Prabha S, Sahoo SK, Labhasetwar V. Rapid endolysosomal escape of poly (D,L-lactide-co-glycolide) nanoparticles: Implications for drug and gene delivery. FASEB J. 2002;16:1217-1226.

22. Prabha S, Zhou WZ, Panyam J, Labhasetwar V. Size-dependency of nanoparticle-mediated gene transfection: Studies with fractionated nanoparticles. Int J Pharm. 2002;244:105-115.

23. Sahoo SK, Panyam J, Prabha S, Labhasetwar V. Residual polyvinyl alcohol associated with poly (D, L-lactide-co-glycolide) nanoparticles affects their physical properties and cellular uptake. J Control Release. 2002:82:105-114.

24. Cartiera MS, Johnson KM, Rajendran V, Caplan MJ, Saltzman WM. The uptake and intracellular fate of PLGA nanoparticles in epithelial cells. Biomaterials. 2009;30:2790-2798.

25. Kim TY, Kim DW, Chung JY, Shin SG, Kim SC, Heo DS. Phase I and pharmacokinetic study of Genexol-PM, a cremophor-free, polymeric micelle-formulated paclitaxel, in patients with advanced malignancies. Clin Cancer Res. 2004;10:3708-3716.

26. Kim DW, Kim SY, Kim HK, Kim SW, Shin SW, Kim JS. Multicenter phase II trial of Genexol-PM, a novel cremophor-free, polymeric micelle formulation of paclitaxel, with cisplatin in patients with advanced nonsmall-cell lung cancer. Ann Oncol. 2007;18:2009-2014.

27. Lee KC, Chung HC, Im SA, Park YH, Kim CS, Kim SB. Multicenter phase II trial of Genexol-PM, a cremophor-free, polymeric micelle formulation of paclitaxel, in patients with metastatic breast cancer. Breast Cancer Res Treat. 2008;108:241-250.

28. Deng X, Zhou S, Li X, Zhao J, Yuan M. In vitro degradation and release profiles for poly-dl-lactide-poly(ethylene glycol) microspheres containing human serum albumin. J Control Release. 2001;71: $165-173$.

29. Xu WS, Wood-Adams PM, Robertson CG. Measuring local viscoelastic properties of complex materials with tapping mode atomic force microscopy. Polymer. 2006;47:4798-4810.

30. Chan JM, Zhang LF, Yuet KP, et al. PLGA-lecithin-PEG core-shell nanoparticles for controlled drug delivery. Biomaterials. 2009;30: $1627-1634$.

31. Sandstrom K, Hakansson L, Lukinius A, Venge P. A method to study apoptosis in eosinophils by flow cytometry. J Immunol Methods. 2000; 240:55-68.

32. Suh H, Jeong B, Liu F, Kim SW. Cellular uptake study of biodegradable nanoparticles in vascular smooth muscle cells. Pharm Res. 1998;15: 1495-1498.

33. Hu Y, Xie JW, Tong YW, Wang CH. Effect of PEG conformation and particle size on the cellular uptake efficiency of nanoparticles with the HepG2 cells. J Control Release. 2007;118:7-17. 
34. Yamamoto H, Kuno Y, Sugimoto S, Takeuchi H, Kawashima Y. Surface-modified PLGA nanosphere with chitosan improved pulmonary delivery of calcitonin by mucoadhesion and opening of the intercellular tight junctions. J Control Release. 2005;102:373-381.

35. Rosen H, Abribat T. The rise and rise of drug delivery. Nat Rev Drug Discov. 2005;4:381-385.

36. Wattendorf U, Merkle HP. PEG-ylation as a tool for the biomedical engineering of surface modified microparticles. J Pharm Sci. 2008;97: 4655-4669.

37. Zauner W, Farrow NA, Haines AM. In vitro uptake of polystyrene microspheres: effect of particle size, cell line and cell density. J Control Release. 2001;71:39-51.

38. Foster KA, Yazdanian M, Audus KL. Microparticulate uptake mechanisms of in-vitro cell culture models of the respiratory epithelium. J Pharm Pharmacol. 2001;53:57-66.

39. Grabe M, Oster G. Regulation of organelle acidity. J Gen Physiol. 2001; $117: 329-344$
40. Watson P, Jones AT, Stephens DJ. Intracellular trafficking pathways and drug delivery: fluorescence imaging of living and fixed cells. Adv Drug Deliv Rev. 2005;57:43-61.

41. Luo D, Saltzman WM. Synthetic DNA delivery systems. Nat Biotechnol. 2000;18(1):7-33.

42. Soppimath KS, Aminabhavi TM, Kulkarni AR, Rudzinski WE. Biodegradable polymeric nanoparticles as drug delivery devices. J Control Release. 2001;70:1-20.

43. Hans ML, Lowman AM. Biodegradable nanoparticles for drug delivery and targeting. Curr Opin Solid State Mater Sci. 2002;6:319-327.

44. Prego C, Garcia M, Torres D, Alonso MJ. Transmucosal macromolecular drug delivery. J Control Release. 2005;101:51-62.

45. Rieux A, Fievez V, Garinot M, Schneider YJ, Preat V. Nanoparticles as potential oral delivery systems of proteins and vaccines: a mechanistic approach. J Control Release. 2006;116(1):1-27.

\section{Publish your work in this journal}

The International Journal of Nanomedicine is an international, peerreviewed journal focusing on the application of nanotechnology in diagnostics, therapeutics, and drug delivery systems throughout the biomedical field. This journal is indexed on PubMed Central, MedLine, CAS, SciSearch $\AA$, Current Contents ${ }^{\circledR} /$ Clinical Medicine,
Journal Citation Reports/Science Edition, EMBase, Scopus and the Elsevier Bibliographic databases. The manuscript management system is completely online and includes a very quick and fair peer-review system, which is all easy to use. Visit http://www.dovepress.com/ testimonials.php to read real quotes from published authors. 